\title{
Chronic Obstructive Pulmonary Disease and Diabetes Mellitus: A Systematic Review of the Literature
}

\author{
Sven Gläser ${ }^{a}$ Stefan Krüger ${ }^{b}$ Martin Merkel ${ }^{c}$ Peter Bramlage ${ }^{d}$ \\ Felix J.F. Herth ${ }^{\mathrm{e}}$ \\ ${ }^{a}$ Department of Internal Medicine B - Cardiology, Intensive Care, Pulmonary Medicine and Infectious Diseases \\ and Scientific Division of Pneumological Research and Pneumological Epidemiology, University of Greifswald, \\ Greifswald, 'b Department of Pneumology, Allergology, Sleep- and Respiration Medicine, Florence-Nightingale \\ Hospital, Düsseldorf, ' First Department of Internal Medicine (Gastroenterology, Endocrinology, Diabetes \\ and Metabolism), Asklepios Clinic St. Georg, Hamburg, dInstitut für Pharmakologie und Präventive Medizin, \\ Mahlow, and e Department of Pneumology and Critical Care Medicine, Thoraxklinik University of Heidelberg and \\ Translational Lung Research Center (Member of the German Lung Research Foundation), Heidelberg, Germany
}

\section{Key Words}

Chronic obstructive pulmonary disease - Type-2 diabetes .

Pathophysiological relationship · Inflammation

\begin{abstract}
The objective of this systematic review was to discuss our current understanding of the complex relationship between chronic obstructive pulmonary disease (COPD) and type-2 diabetes mellitus (T2DM). We performed a systematic search of the literature related to both COPD and diabetes using PubMed. Relevant data connecting both diseases were compiled and discussed. Recent evidence suggests that diabetes can worsen the progression and prognosis of COPD; this may result from the direct effects of hyperglycemia on lung physiology, inflammation or susceptibility to bacterial infection. Conversely, it has also been suggested that COPD increases the risk of developing T2DM as a consequence of inflammatory processes and/or therapeutic side effects related to the use of high-dose corticosteroids. In conclusion, although
\end{abstract}

there is evidence to support a connection between COPD and diabetes, additional research is needed to better understand these relationships and their possible implications.

(c) 2015 S. Karger AG, Basel

\section{Introduction}

Sixty-five million people are estimated to suffer from moderate to severe chronic obstructive pulmonary disease (COPD), which is predicted to become the third leading cause of death worldwide by 2030 [1]. COPD is characterized by persistent and usually progressive airflow limitation, which occurs in response to long-term exposure to noxious particles or gases (e.g. air pollution or smoking). These irritants cause an inflammatory response in the lungs, leading to shortness of breath, coughing and sputum production. In addition, in the majority of cases, acute exacerbation of COPD (AECOPD) is triggered by respiratory tract infections. Diagnosis of COPD severity is based on 
symptoms, exacerbation frequency and the degree of airflow limitation as assessed by pulmonary function testing. Treatment of COPD involves lifestyle modifications as well as the use of pharmacotherapies including bronchodilators and corticosteroids for AECOPD. Notably, COPD is known to be associated with several important chronic comorbid diseases, including hypertension, cardiovascular disease, obstructive sleep apnea and type-2 diabetes mellitus (T2DM) which are already partially interrelated [2-6].

Diabetes mellitus is also a chronic condition with severe global consequences. Indeed, in 2013, there were an estimated 382 million people (8.3\% of the adult population) suffering from diabetes worldwide. However, approximately half of those with diabetes remain undiagnosed. Moreover, the rate of diabetes has steadily increased, and it is predicted that there will be around 600 million people with this condition by 2035 [7]. T2DM, which represents about $90 \%$ of diabetes cases, results mainly from a sedentary lifestyle and adiposity, together with genetic predisposition. T2DM is characterized by the failure of blood glucose control due to a combination of insulin resistance and pancreatic beta cells not functioning. As a consequence of its pathogenesis, T2DM is commonly associated with diabetic dyslipidemia (i.e. an increase in plasma triglycerides, remnant lipoprotein and small dense low-density lipoprotein and a decrease in high-density lipoprotein), fatty-liver disease and a chronic inflammatory state. Over time, diabetes can lead to serious complications, including macrovascular (cardiovascular) and microvascular disease (e.g. diabetic nephropathy, retinopathy and neuropathy).

Approximately $10 \%$ of patients with diabetes also suffer from COPD $[8,9]$; this is a grey zone, however, and there is a need to distinguish COPD from obesity-related pulmonary dysfunction. Recent studies have shown that T2DM can worsen the progression and prognosis of COPD, increasing the odds of COPD-related mortality [10-12]. On the other hand, diabetes-associated adiposity has been shown to have a protective effect in patients with COPD, even reducing mortality [13]. Nevertheless, controversy remains as to whether there is a causal relationship between T2DM and COPD, and it is also possible that this interaction only occurs in a subset of patients (i.e. diabetics with neuropathy) [14]. Conversely, it has also been suggested that COPD constitutes an important risk factor for the development and/or progression of T2DM [2, 1517], a phenomenon that does not apply to type-1 diabetes. Thus, although COPD and T2DM represent distinct disease entities, there might indeed be a pathophysiological connection that links these important chronic conditions.
It is of scientific and clinical importance to obtain an understanding of the risk factors that drive the development of T2DM and/or COPD and the potential consequences of therapeutic intervention for these diseases. Here, we have compiled and reviewed the available data on the interaction between COPD and T2DM. We also discuss the implications of this research. Taken together, this information not only highlights the complex relationship that might exist between COPD and T2DM, but also contributes to our knowledge regarding preventative care for patients.

\section{Methods}

Systematic Search Strategy

In March 2014, an electronic literature search was performed via PubMed. The terms 'diabetes' and 'hyperglycemia' were searched in combination with 'chronic obstructive pulmonary disease' and 'COPD'. This search was then extended by manual screening of the references of the included papers to identify additional supporting information.

\section{Study Selection}

Included studies fulfilled the following criteria: (1) they were published as a primary research article in a peer-reviewed journal, (2) they reported results that either indirectly or directly yielded insight into the relationship between COPD and diabetes and (3) they were written in English. A 2-reviewer system was employed. One individual performed the PubMed search and screened the abstracts to exclude irrelevant articles. The relevant full-text articles were then reviewed and discussed by 2 reviewers to assess quality. A flow diagram outlining our systematic literature search on the interaction between COPD and diabetes is shown in figure 1 .

\section{The Adverse Effects of Hyperglycemia on Lung Function}

Although recent evidence seems to indicate that diabetes and elevated blood glucose constitute important comorbidities that have an impact on lung function, the mechanistic explanation for this relationship remains illdefined. Nevertheless, it is possible that hyperglycemia leads directly to adverse effects on the lungs (i.e. glycosylation of the connective tissues, reduced pulmonary elastic recoil, increased muscle weakness and/or inflammation), which can result in restrictive alterations. In this regard, studies have demonstrated that pulmonary function tests are significantly decreased in subjects with T2DM in comparison to healthy controls [18-20]; this might be the result of direct exposure to elevated blood sugar [21,22] (table 1). In line with this, it was reported that metabolic 
Fig. 1. Flow diagram showing our systematic literature search on the interaction between COPD and diabetes.

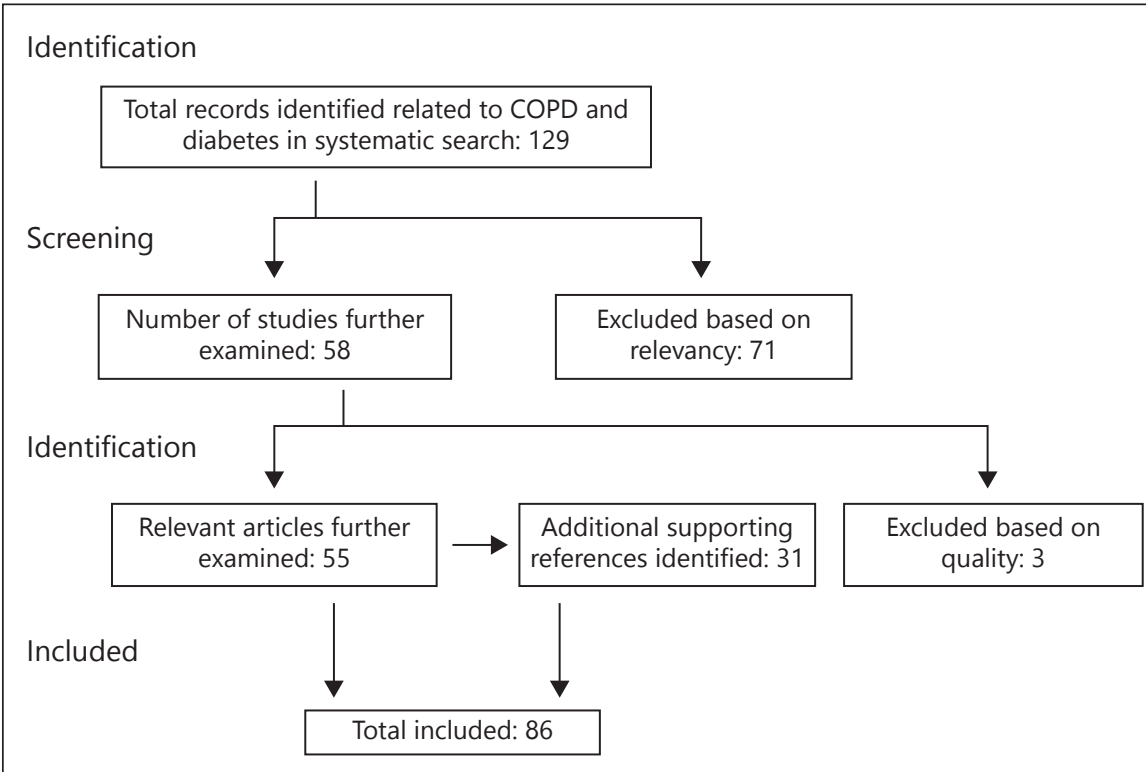

Table 1. Key studies suggesting that hyperglycemia and T2DM adversely affect lung function

\begin{tabular}{|c|c|c|}
\hline Population & Principal findings & Ref. \\
\hline Patients with T2DM vs. nondiabetics & significantly decreased pulmonary function tests in T2DM patients & {$[18-20]$} \\
\hline $\begin{array}{l}495 \text { diabetic patients, } 352 \text { of whom showed } \\
\text { inadequate control (HbA1c }>7 \%)\end{array}$ & decreased pulmonary function tests in T2DM linked with hyperglycemia & {$[21]$} \\
\hline 3,911 women (aged $60-79$ years) & $\begin{array}{l}\text { lung function measures were inversely associated with insulin } \\
\text { resistance and T2DM }\end{array}$ & {$[22]$} \\
\hline $\begin{array}{l}155 \text { patients ( } 55 \text { with AECOPD and T2DM } \\
\text { and various controls) and } 30 \text { healthy subjects }\end{array}$ & $\begin{array}{l}\text { pulmonary hypertension was more severe in patients with COPD } \\
\text { and T2DM }\end{array}$ & {$[33]$} \\
\hline $\begin{array}{l}\text { 9,581 apparently healthy nonsmoking } \\
\text { adult males }\end{array}$ & $\begin{array}{l}\text { metabolic syndrome, systemic inflammation and insulin resistance } \\
\text { are important risk factors for reduced lung function }\end{array}$ & {$[23]$} \\
\hline $\begin{array}{l}1,811,228 \text { individuals in the general } \\
\text { population }\end{array}$ & $\begin{array}{l}\text { diabetes increases the risk of developing severe pulmonary conditions, } \\
\text { such as asthma and COPD }\end{array}$ & {$[32]$} \\
\hline $\begin{array}{l}10,129 \text { diabetic and nondiabetic subjects } \\
\text { with/without COPD and a }>10 \text {-pack-year } \\
\text { history of smoking }\end{array}$ & $\begin{array}{l}\text { subjects with diabetes displayed reduced pulmonary function along } \\
\text { with significant reductions in exercise capacity and quality of life } \\
\text { across the COPD functional stages }\end{array}$ & {$[25]$} \\
\hline
\end{tabular}

HbA1c = Glycated hemoglobin

syndrome, insulin resistance and systemic inflammation constitute important risk factors for reduced lung function in healthy, nonsmoking subjects [23], which suggest that even in the absence of smoking, diabetes can lead to similar effects on pulmonary function. It has also been proposed that reduced lung volume and airflow limitation might be considered as chronic complications of
T2DM [24]. In fact, diabetic subjects have been found to display reduced pulmonary function even after controlling for known risk factors, along with significant reductions in exercise capacity and quality of life across functional stages of airflow limitation [25]. Notably, even though forced expiratory volume in $1 \mathrm{~s}\left(\mathrm{FEV}_{1}\right)$ and forced vital capacity (FVC) were found to be consistently lower 
Table 2. Studies suggesting that T2DM can worsen outcomes in COPD/AECOPD patients

\begin{tabular}{|c|c|c|}
\hline Population & Principal findings & Ref. \\
\hline $\begin{array}{l}\text { 2,164 clinically stable COPD patients and } 582 \\
\text { smokers/nonsmokers with normal lung function }\end{array}$ & $\begin{array}{l}\text { diabetes with COPD increased the odds of mortality and was associated with a } \\
\text { poorer prognosis }\end{array}$ & {$[10]$} \\
\hline $\begin{array}{l}172 \text { patients admitted for AECOPD } \\
\text { ( } 246 \text { admissions) }\end{array}$ & $\begin{array}{l}\text { patients with diabetes and AECOPD showed increased length of hospitalization } \\
\text { and mortality }\end{array}$ & [12] \\
\hline 590 patients admitted for AECOPD & $\begin{array}{l}\text { diabetes was associated with an increased length of hospital stay for AECOPD } \\
\text { patients }\end{array}$ & [35] \\
\hline 256 patients admitted for AECOPD & $\begin{array}{l}\text { a } 8.7 \text {-year follow-up indicated an increased long-term mortality associated with } \\
\text { diabetes }\end{array}$ & [36] \\
\hline 416 patients admitted for AECOPD & $\begin{array}{l}\text { a } 2 \text {-year follow-up revealed that diabetic patients displayed an increased } \\
\text { mortality rate }\end{array}$ & [37] \\
\hline 47 consecutive patients admitted for AECOPD & $\begin{array}{l}\text { continuous glucose monitoring indicated that the length of hospital stay after } \\
\text { AECOPD increased by } 10 \% \text { for each } 1-\mathrm{mM} \text { increase in mean glucose }\end{array}$ & [40] \\
\hline $\begin{array}{l}284 \text { patients admitted for AECOPD with a lower } \\
\text { respiratory infection }\end{array}$ & $\begin{array}{l}\text { patients with diabetes and AECOPD showed an increased length of hospital stay } \\
\text { and mortality, and hyperglycemia (blood glucose } \geq 7 \text { ) is significantly associated } \\
\text { with adverse events (each 1-mM increment in blood glucose increases the absolute } \\
\text { risk of adverse outcomes by } 15 \% \text { ) }\end{array}$ & [11] \\
\hline $\begin{array}{l}137 \text { patients admitted for AECOPD and showing } \\
\text { initial success with noninvasive ventilation }\end{array}$ & $\begin{array}{l}\text { hyperglycemia (blood glucose }>11 \mathrm{~mm} \text { ) was associated with a late failure } \\
\text { of noninvasive ventilation after initial success }\end{array}$ & [44] \\
\hline $\begin{array}{l}88 \text { COPD patients admitted with an episode of } \\
\text { hypercapnic respiratory failure and requiring } \\
\text { noninvasive ventilation }\end{array}$ & $\begin{array}{l}\text { hyperglycemia (blood glucose } \geq 7 \mathrm{mM} \text { ) within } 24 \text { h of admission could be used } \\
\text { to predict clinical outcome }\end{array}$ & [45] \\
\hline
\end{tabular}

in diabetic subjects, these deficits did not seem to be progressive in the long term [26].

With regard to decreased lung function in diabetic patients, a study in rats confirmed that hyperglycemia has the potential to impact the respiratory system by inducing oxidative stress, structural changes in the lung tissue and altered gas exchange [27]. Moreover, postmortem studies in humans have indicated that the epithelial and capillary basal membranes of the alveoli are significantly thicker in diabetic subjects when compared to age-matched controls [28]; this is consistent with the notion that hyperglycemia can lead to structural modifications in the lung. In addition, an experimental model of hyperglycemia led to increased levels of inflammatory cytokines, including interleukin (IL)-6, tumor necrosis factor alpha (TNFa) and IL18 [29]. C-reactive protein levels were also found to be elevated in individuals showing impaired glucose tolerance $[30,31]$, and the ECLIPSE (Evaluation of COPD Longitudinally to Identify Predictive Surrogate Endpoints) study observed increased systemic inflammation based on these levels when diabetes was a comorbidity of COPD [10]. This emerging model suggests that hyperglycemia can drive inflammatory responses, which can ultimately lead to restrictive changes in the lung tissue and reduced pulmonary function. Notably, such alterations would have the potential to exacerbate ongoing immune-related processes, thereby driving the pathophysiology of COPD.

\section{The Impact of Diabetes on Patients with COPD}

\section{Effects of Preexisting Diabetes on the Course of COPD/ $A E C O P D$}

Several key pieces of evidence have recently suggested that preexisting T2DM leads to adverse effects in patients suffering from COPD (see table 2). More recently, the negative effects of diabetes on COPD were confirmed by the ECLIPSE study, a multicenter investigation that evaluated 2,164 clinically stable COPD subjects and 582 individuals with normal lung function (both smokers and nonsmokers) in order to identify predictors of disease progression. ECLIPSE identified that diabetes increased the odds of mortality when coexistent with COPD and that it was associated with higher Medical Research Council dyspnea scores as well as a reduced 6-min walk distance [10]. In addition to affecting the prognosis of 
COPD patients, it has been suggested that diabetes increases the risk of developing severe pulmonary conditions, such as asthma and COPD [32]. Furthermore, pulmonary hypertension has been found to be more severe in patients with COPD and T2DM [33]. The impact on the actual daily quality of life in COPD patients, however, is a matter of controversy $[25,34]$.

Diabetic patients with AECOPD, on the other hand, were found to frequently (in $50-80 \%$ of patients) display hyperglycemia during their hospital stay and exhibit an increased length of hospitalization and mortality when compared to patients without diabetes [11, 12, 35-39]. A blood glucose level of $\geq 7 \mathrm{~mm}$ has been found to be significantly associated with these adverse consequences, with the risk for combined outcome (i.e. longer hospital stay and death) increasing by $15 \%$ for each 1-mM increment in blood glucose [11]. Moreover, it was also reported that the length of hospital stay after AECOPD increased by $10 \%$ for each 1 -mM increase in mean glucose [40]. These findings suggest a potentially negative impact of the diabetic condition on AECOPD. This is not surprising, as other acute conditions having been shown to induce hyperglycemia as a result of stress (e.g. myocardial infarction and stroke), irrespective of baseline glucose tolerance $[41,42]$. Thus, a large proportion of patients experiencing AECOPD have the potential to experience the negative effects of hyperglycemia. Nevertheless, these results have not been observed in all studies that have examined hospitalized AECOPD patients, and it has been suggested that hypoglycemia (rather than hyperglycemia) may actually be more detrimental for outcome (i.e. longer hospitalization) [43]. In addition, with regard to the treatment of AECOPD, it has been reported that hyperglycemia (i.e. blood glucose $>11 \mathrm{mM}$ ) is independently associated with a late failure (i.e. after $48 \mathrm{~h}$ ) of noninvasive ventilation following initial success [44]. Accordingly, it was demonstrated that hyperglycemia (blood glucose $\geq 7 \mathrm{mM}$ ) within $24 \mathrm{~h}$ of admission could be used to predict clinical outcome in COPD patients presenting with acute hypercapnic respiratory failure and requiring noninvasive ventilation [45]. Nevertheless, it is still not known whether acute hyperglycemia occurring during AECOPD-related hospitalization is a direct cause of poor outcomes or is simply a marker of other adverse factors (e.g. treatment modification).

In spite of the overwhelming findings demonstrating the potential deleterious role of diabetes in the treatment, prognosis and progression of $\mathrm{COPD}$, there are also some data that suggest positive effects related to diabetes in COPD. Although a recent systematic review described

COPD and T2DM: Systematic Review of the Literature that diabetes was associated with increased long-term mortality in patients admitted for AECOPD, the analysis also revealed a reduction in short-term COPD-related mortality in those with diabetes [46]. This protective effect of diabetes was also observed in a study by McGhan et al. [47], who reported that diabetes was associated with a reduction in readmissions for patients who had survived an episode of AECOPD . So far, it remains unclear how diabetes could lead to these types of protective effects, although preferential care of diabetic patients could represent a contributing factor.

\section{Diabetes, COPD and Infection}

There is some evidence to support the fact that diabetes and hyperglycemia can augment the ability of bacteria to infect the lungs of COPD patients $[11,48]$. Indeed, elevated glucose concentrations may directly stimulate bacterial growth or promote bacterial interaction with the airway epithelium [49]. It is also possible that certain facets of the immune system become impaired during hypoglycemia-induced immunomodulation, leading to increased susceptibility to bacterial pathogens. Indeed, there is a precedence for diminished immunity in diabetic patients, including impaired polymorphonuclear leukocyte phagocytic functions [50]. In this regard, a recent study using a mouse model of cystic fibrosis-related diabetes suggested that hyperglycemia leads to reduced bacterial clearance from the lungs, despite the formation of a robust inflammatory response [51]. Taking these data into consideration, it is interesting that Moretti et al. [44] reported that all of the patients admitted for AECOPD, who presented with elevated blood glucose levels and failed noninvasive ventilation, developed pulmonary infections that may have contributed to poor outcome. Therefore, susceptibility to bacterial infection could represent a life-threatening complication associated with hyperglycemia in COPD patients with diabetes.

\section{The Impact of COPD on Patients with Diabetes}

\section{The Effect of Preexisting COPD on Diabetes Manifestation}

Even though diabetes has been suggested as a comorbidity that can worsen COPD progression and prognosis, recent evidence also supports that COPD may represent a valuable predictor for the development of diabetes (table 3). Indeed, when considering baseline lung function, according to the modified Global Initiative for Obstructive Lung Disease (GOLD) criteria, subjects with 
Table 3. Studies suggesting that COPD increases the risk of T2DM

\begin{tabular}{|c|c|c|}
\hline Population & Principal findings & Ref. \\
\hline $\begin{array}{l}20,296 \text { subjects } \geq 45 \text { years old stratified by baseline lung } \\
\text { function data according to the modified GOLD criteria }\end{array}$ & $\begin{array}{l}\text { over } 5 \text { years of follow-up, subjects with GOLD stage } 3 \text { or } 4 \text { COPD } \\
\text { displayed a higher prevalence of diabetes }\end{array}$ & {$[2]$} \\
\hline 1,041 COPD patients & incidence of diabetes increases with worsening GOLD score & {$[52]$} \\
\hline 103,614 female nurses & $\begin{array}{l}\text { after an 8-year follow-up, it was found that COPD was associated with an } \\
\text { increased risk of T2DM }\end{array}$ & {$[15]$} \\
\hline Danish nationwide study of 7.4 million individuals & $\mathrm{COPD}$ is associated with higher rates of diabetes & {$[53]$} \\
\hline $\begin{array}{l}1,204,100 \text { members of the general population aged } \\
\geq 35 \text { years }\end{array}$ & $\begin{array}{l}\text { COPD is associated with an increased rate of diabetes, with the greatest } \\
\text { effect seen in young current smokers and non-smokers of } 45-55 \text { years of } \\
\text { age COPD is associated with a reduction in diabetes in older age groups }\end{array}$ & {$[54]$} \\
\hline Initially nondiabetic men and/or women & $\begin{array}{l}\text { during follow-ups of } 4-13.9 \text { years, it was found that impaired lung } \\
\text { function could be used to predict diabetes }\end{array}$ & {$[57-62]$} \\
\hline $\begin{array}{l}56 \text { nonhypoxemic COPD patients and } 29 \text { healthy } \\
\text { subjects }\end{array}$ & $\begin{array}{l}\text { insulin resistance in COPD patients is linked to inflammatory mediators } \\
\text { including IL- } 6 \text { and TNF } \alpha \text { soluble receptor-I }\end{array}$ & {$[71]$} \\
\hline
\end{tabular}

GOLD stage 3 or 4 COPD had a higher prevalence of diabetes [2], a result later confirmed by another study [52]. Thus, COPD appears to constitute an important risk factor for developing T2DM, and several studies have identified that the prevalence of diabetes is higher in COPD patients $[15,16,53-55]$. Over a follow-up period of 20.9 years, the Normative Aging Study found that $\mathrm{FVC}, \mathrm{FEV}_{1}$ and maximal midexpiratory flow rate (MMEF) were associated with insulin resistance [56]. Likewise, 6 other studies, which included follow-ups of 4-13.9 years, observed that impaired lung function is a predictor of diabetes [57-62]. Nevertheless, although an association between reduced pulmonary function and the incidence of diabetes was observed by analysis of data from the National Health and Nutrition Examination Survey Epidemiologic Follow-Up Study, a link between COPD and diabetes could not be confirmed [63]. A later report by Wannamethee et al. [64] concluded that while restrictive impairment of lung function was associated with the incidence of T2DM, obstructive impairment was not. Notably, 1 study did not observe any increase in the incidence of diabetes in COPD patients [65]; this could have resulted from the large population of underweight individuals in the cohort.

\section{Systemic Inflammation in Metabolic Syndrome and} the Link to COPD

A plausible explanation for the association of COPD and T2DM incidence may be that COPD leads to diminished physical activity and the progressive development of metabolic syndrome. In fact, Park and Larson [66] recently reported that over half of the COPD patients in their study presented with metabolic syndrome, with greater physical activity and less sedentary time being associated with lower rates of this comorbidity. Nevertheless, it was also proposed that the increased rates of metabolic syndrome in COPD patients could be linked to systemic inflammation $[67,68]$, supporting a more primary and direct role for COPD pathogenesis in the induction of T2DM $[69,70]$. Indeed, insulin resistance has been linked to inflammatory mediators (e.g. IL-6 and TNFa soluble receptor-I) in patients with COPD [71]. Moreover, lowgrade systemic inflammation has been shown to predict the incidence of T2DM $[72,73]$. Takenaka et al. [74] recently developed a mouse model in which IL-18 was expressed in the lungs to induce COPD-like symptoms. Interestingly, these mice developed impaired glucose tolerance over time, supporting a directlink between pulmonary inflammation and diabetes. Nevertheless, exposure to in- 
Table 4. Studies suggesting that corticosteroid therapy for COPD increases the risk of T2DM onset and progression

\begin{tabular}{|c|c|c|}
\hline Population & Principal findings & Ref. \\
\hline $\begin{array}{l}18,226 \text { diabetes patients newly initiated on } \\
\text { metformin or sulfonylurea; } 5.9 \% \text { with COPD } \\
\text { were stratified based on corticosteroid dose }\end{array}$ & $\begin{array}{l}\text { patients with both diabetes and COPD display an increased risk of diabetes- } \\
\text { related hospitalizations upon high-dose corticosteroid therapy }\end{array}$ & {$[77]$} \\
\hline $\begin{array}{l}1,698 \text { patients with and without diabetes } \\
\text { (approx. } 85 \% \text { with COPD) }\end{array}$ & $\begin{array}{l}\text { dose-dependent effect of inhaled corticosteroid therapy on serum glucose } \\
\text { concentrations in patients with diabetes }\end{array}$ & {$[78]$} \\
\hline 388,584 patients treated for respiratory disease & $\begin{array}{l}30,167 \text { patients had diabetes onset during the } 5.5 \text {-year follow-up; the risk for } \\
\text { diabetes onset and progression increased with higher inhaled corticosteroid } \\
\text { doses similar to those currently prescribed for COPD }\end{array}$ & [79] \\
\hline
\end{tabular}

flammation occurring during AECOPD has not been found to have effects on long-term glycemic control in patients with T2DM [75]. Therefore, future studies on the role of inflammation in the pathogenesis of diabetes should expand our understanding of the potential interaction of inflammatory processes that occur during COPD as well as the development and progression of diabetes.

\section{The Role of Corticosteroid Therapy in Diabetes Onset and Progression}

Another possible mechanistic explanation for the increased prevalence of diabetes in COPD patients relates to therapeutic interventions for AECOPD (table 4). Current international guidelines suggest a course of at least 7 days of systemic glucocorticoid therapy for the management of AECOPD, and high doses of inhaled corticosteroids are frequently used. Although the short-term benefits of these treatments are clear, it is known that prolonged exposure to corticosteroids can lead to substantial side effects in COPD patients and even death [76]. In this respect, there is evidence to support the notion that steroid therapy for COPD can lead to the development or worsening of diabetes.

A recent retrospective study of claims data from the Australian Government Department of Veterans' Affairs revealed that patients with both diabetes and COPD display an increased risk of diabetes-related hospitalizations upon high-dose corticosteroid therapy [77]. Therefore, the use of corticosteroids might not be recommended in diabetic patients due to the potential for a dose-dependent augmentation in blood glucose levels and an increased risk of diabetes progression [78, 79]. The Department's cooperative study group found that hyperglycemia occurred significantly more often inglucocorticoid-treated AECOPD patients than in controls, with rehospitalization rates due to serious infections being higher in the long-term-steroid treatment group [80]. Burt et al. [81] describe that treatment with a corticosteroid (prednisolone) led to a circadian cycle in COPD patients, with hyperglycemia occurring in the afternoon and evening. Moreover, the use of inhaled corticosteroids was associated with a $34 \%$ increase in the rate of diabetes [79]. Strikingly, this risk for diabetes onset and progression was shown to increase in response to higher inhaled-corticosteroid doses, which are similar to those currently prescribed for COPD treatment [79].

There is also some conflicting data with regard to corticosteroid use and diabetes. Although it was reported that elderly patients using oral corticosteroids showed an increased risk for diabetes, inhaled-corticosteroid users did not [82]. Another investigation involving elderly patients treated with inhaled-corticosteroids observed no link with diabetes [83]. In addition, in a retrospective analysis of double-blind, controlled trials, no connection between corticosteroid use and diabetes could be confirmed [84]. Therefore, whether high-dose and/or longterm steroid use in COPD patients causes T2DM is a topic that will require further investigation. Considering that inhaled-steroid use is usually linked to disease severity 
Fig. 2. Proposed mechanisms for the inter-

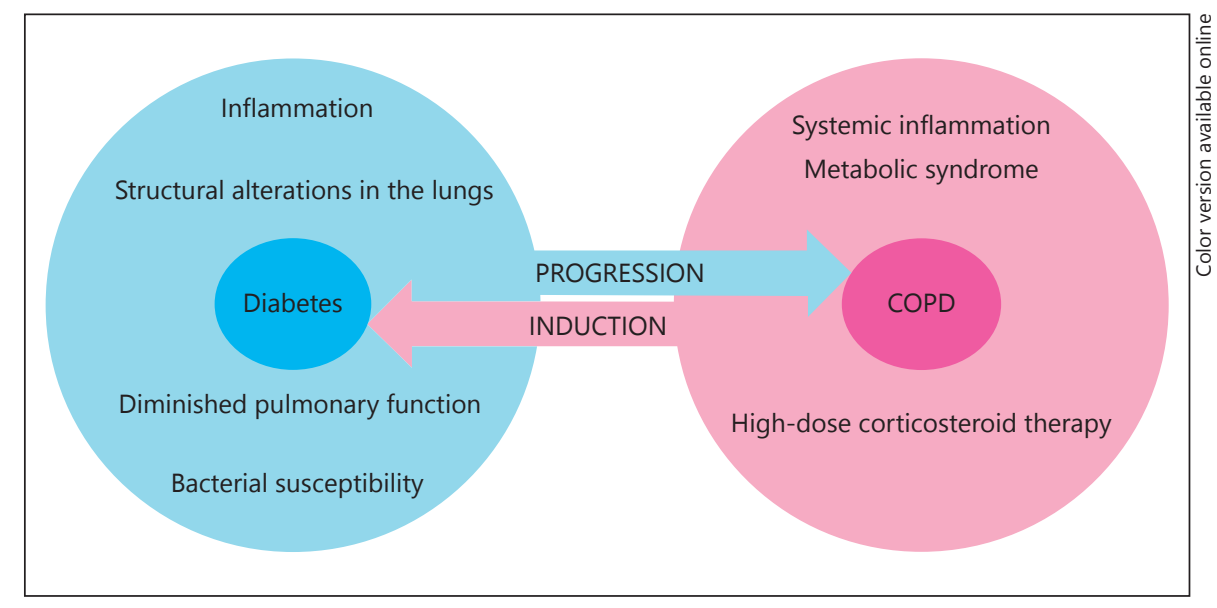
action between diabetes and COPD.

and exacerbation frequency, it is possible that medications as well as disease will be found to account for the interaction between inhaled steroids and diabetes in COPD. However, the possible role of steroid therapy in diabetes development and the dangers of corticosteroid use in COPD patients with diabetes as a comorbidity must be considered in the clinical setting.

Although corticosteroids have been well-accepted as one option for the treatment of specific COPD phenotypes, it has been suggested that the optimal dose and the length of the treatment regimen need to be better-defined due to the substantial risk of possible side effects, including diabetes [85]. In this regard, a recent randomized clinical trial, REDUCE (Reduction in the Use of Corticosteroids in Exacerbated COPD), compared short-term (5-day) systemic glucocorticoid treatment with the conventional 14-day treatment in patients presenting to the emergency department with AECOPD [86]. It was found that the 5-day regimen was not inferior to the 14-day treatment with regard to a reexacerbation within 6 months of follow-up. Investigations have now indicated that lowering steroid doses may be appropriate and beneficial in the treatment of COPD $[87,88]$. This suggests that the current standard of care could be effectively altered to reduce the duration and dose of treatment, thereby diminishing the potential for therapeutic side effects (e.g. the development of diabetes). However, more investigations will be required to verify the efficacy of these treatment strategies. Increased selectivity with regard to the patients receiving steroid therapy (i.e. the best risk-to-benefit ratio) has been encouraged [89]. Overall, a better understanding of how COPD therapies can influence the development and progression of T2DM as well as the improvement of therapeutic regimens for AECOPD can lead to safer and more effective patient care.

\section{Discussion}

\section{Principal Findings}

Our analysis of the current literature concerning the interaction between COPD and diabetes has identified key evidence to support the existence of a complex interaction between these conditions. Indeed, several mechanistic explanations have been proposed to contribute to the relationship between COPD and diabetes (see fig. 2). Diabetes may worsen the progression and prognosis of COPD via the direct consequences of hyperglycemia on lung physiology, inflammation and/or susceptibility to bacterial infection. Conversely, COPD may increase the risk of developing T2DM due to the inflammatory processes and/or the therapeutic side effects related to the use of corticosteroids. However, future research involving collaborations between pneumologists and diabetologists will be essential to fully elucidate the interaction between COPD and diabetes.

\section{Strengths and Limitations of the Studies}

In general, the investigations pertaining to the relationship between COPD and diabetes were well controlled. Nevertheless, there were several limitations. For example, many of the studies, in particular those that involved analysis of patients hospitalized for AECOPD, enrolled only a small number of participants. In addition, the population of patients presenting with diabetes and/or COPD is a complex one, often presenting with other important comorbidities, which complicates interpretations relating to final outcome (e.g. length of hospitalization and death). It is also possible that the observed relationship between these conditions is attributable to environmental factors (e.g. smoking) instead of pathophysiological interactions. 
Indeed, in most cases, COPD is the result of smoking, and some studies indicate that smoking may be a risk factor for diabetes [90]. Thus, it is not yet entirely clear whether the development of diabetes might simply occur in parallel to rather than as a consequence of COPD (i.e. that therapeutic, environmental or common lifestyle factors are actually responsible). Moreover, in this respect, the wide range of COPD and T2DM patients cannot be overlooked. Indeed, COPD represents an umbrella term for similar conditions that display diverse etiologies, and the same can be said for T2DM (e.g. insulinopenic and insulin-resistant T2DM). As a result, it may be difficult to generalize observations regarding the link between COPD and diabetes in the absence of well-defined patient groups. Finally, as to the use of steroids for treating AECOPD, there is some controversy regarding the appropriate use of this therapeutic intervention due to its side effects. This means that the selection of the patients, the doses and the duration of treatment can all be variable.

\section{Unanswered Questions and Implications for Future Work}

Although there is evidence to suggest complex interactions between COPD and diabetes, additional research will be required in order to better understand these relationships and their possible implications. For instance, it is still not known whether acute hyperglycemia occurring during COPD-related hospitalization is a direct cause of poor outcomes or is simply a marker of other adverse factors (e.g. treatment modification or stress). Therefore, the exact role of hyperglycemia in pulmonary function and inflammation must be elucidated. In addition, it is uncertain whether the inflammatory effects induced by hyperglycemia actually exert a direct influence on COPD symptoms $[91,92]$. A recent randomized controlled trial suggested no effects of statins ( $40 \mathrm{mg}$ simvastatin once daily), which are frequently administered in T2DM, on the time to a first exacerbation in patients with COPD [93]. It also remains unclear which effect mediated by hyperglycemia could contribute the strongest influence on COPD progression. Indeed, any one of the proposed diabetes-associated complications discussed here (i.e. lung physiology, inflammation or enhanced susceptibility to infection) has the potential to be detrimental to patients suffering from COPD. Therefore, despite the fact that recent studies have not been particularly promising [94], continued examination of possible strategies for maintaining strict glycemic control in COPD patients could shed light on the adverse effects of hyperglycemia on pulmonary function. It is also important to identify which antidiabetic treatments might interact with COPD (i.e. augment risk and/or symptoms) in order to determine the most favorable therapeutic options.

Although a link has been established between reduced lung function and the development of diabetes, it has not been clearly demonstrated that this translates into a concrete causal relationship between COPD and diabetes. Indeed, it is possible that reduced lung function and impaired airway resistance simply represent chronic symptoms that are associated with developing diabetes, a topic that needs to be more carefully addressed. In addition, the factors that might contribute to the development of metabolic syndrome in COPD patients need to be more thoroughly examined. Elucidating the potential role of inflammatory conditions in the initiation of metabolic syndrome is of key interest. Cardiovascular disease is also an important comorbidity of both diabetes and COPD $[2,95]$, and investigation of the role that its coexistence could play in the observed interaction between COPD and diabetes would be interesting. Finally, it is not clear what specific effects are induced by corticosteroids that could influence the progression and development of diabetes. Identifying the mechanistic explanations for important side effects could lead to the development of more efficient therapeutic options for patients with COPD in the future.

\section{Clinical Implications of the COPD-Diabetes Connection}

The relationship between T2DM and COPD has significant implications with regard to the clinical management of patients presenting with these morbidities (either alone or in combination). Indeed, both pneumologists and diabetologists must take into account the risks and consequences associated with this potentially important pathophysiological interaction.

Considering our current understanding of the link between COPD and T2DM, pneumologists should actively perform screening for T2DM as a frequent comorbidity of COPD. Indeed, COPD patients can be thought of as being at an increased risk for developing diabetes. With regard to treatment, therapeutic options should be carefully and critically contemplated, taking into account the risk-tobenefit ratios associated with the indication for steroid use. It might be beneficial to consider the reduction of diabetes risk as an objective during the selection of therapeutic approaches for COPD. Furthermore, from the point of view of diabetologists, the influence of hyperglycemia on lung function (i.e. lung physiology, inflammatory processes and 
infection) should be considered in patients with diabetes. Indeed, patients could be routinely screened for lung function as a preliminary measure for determining COPD risk.

In patients with COPD and T2DM, pneumologists and diabetologists should also consider potential treatment interactions associated with the coexistence of these conditions. However, since there is not yet any clear scientific evidence to support general therapeutic recommendations, treatment may be complicated. In this regard, current treatment strategies may need to be based, first and foremost, on ongoing diabetes care. In particular, special attention should be given to the contraindication to metformin for hypoxic (or imminent) respiratory insufficiency. There is a current need to develop specific guidelines that relate to the effective treatment and therapeutic objectives in patients with COPD and diabetes. For this reason, clinical studies comparing the reciprocal efficacy and safety of existing therapies are warranted. Taken together, considering the interaction of COPD and T2DM, a collaboration between pneumologists and diabetologists is fundamental for enhancing patient care.

\section{Acknowledgements}

Funding for this research was obtained by Novartis Pharma $\mathrm{GmbH}$, Nürnberg, Germany. S.G. acts as member of the Community Medicine Research Network of the University of Greifswald (Germany), funded by the German Federal Ministry of Education and Research (01ZZ9603, 01ZZ0103, 01ZZ0403 and 01ZZ0701), the German Ministry of Cultural Affairs and the Social Ministry of the German Federal State of Mecklenburg, Western Pomerania. This work is part of the research project, Greifswald Approach to Individualized Medicine (GANI_MED). The GANI_MED consortium is funded by the German Federal Ministry of Education and Research as well as the Ministry of Cultural Affairs of the German Federal State of Mecklenburg, Western Pomerania (No. 03IS2061A). This study group is further supported by the Kompetenznetz Asthma/COPD (Competence Network Asthma/COPD) funded by the Federal Ministry of Education and Research (FKZ 01GI0881-0888).

\section{Financial Disclosure and Conflicts of Interest}

All authors have received research grants and/or consultancy fees from Novartis Pharma GmbH, Nürnberg, Germany.

\section{References}

1 Duprez DA, Munger MA, Botha J, Keefe DL, Charney AN: Aliskiren for geriatric lowering of systolic hypertension: a randomized controlled trial. J Hum Hypertens 2010;24:600608.

2 Mannino DM, Thorn D, Swensen A, Holguin F: Prevalence and outcomes of diabetes, hypertension and cardiovascular disease in COPD. Eur Respir J 2008;32:962-969.

3 Pamidi S, Tasali E: Obstructive sleep apnea and type 2 diabetes: is there a link? Front Neurol 2012;3:126.

-4 Zamarron C, Garcia Paz V, Morete E, del Campo Matias F: Association of chronic obstructive pulmonary disease and obstructive sleep apnea consequences. Int J Chron $\mathrm{Ob}$ struct Pulmon Dis 2008;3:671-682.

5 McNicholas WT: Chronic obstructive pulmonary disease and obstructive sleep apnea: overlaps in pathophysiology, systemic inflammation, and cardiovascular disease. Am J Respir Crit Care Med 2009;180:692-700.

6 Azuma M, Chin K, Yoshimura C, Takegami M, Takahashi K, Sumi K, Nakamura T, Nakayama-Ashida Y, Minami I, Horita S, et al: Associations among chronic obstructive pulmonary disease and sleep-disordered breathing in an urban male working population in Japan. Respiration 2014;88:234-243.

7 Danaei G, Finucane MM, Lu Y, et al: National, regional, and global trends in fasting plasma glucose and diabetes prevalence since 1980: systematic analysis of health examina- tion surveys and epidemiological studies with 370 country-years and 2.7 million participants. Lancet 2011;378:31-40.

$>8$ Caughey GE, Roughead EE, Vitry AI, McDermott RA, Shakib S, Gilbert AL: Comorbidity in the elderly with diabetes: identification of areas of potential treatment conflicts. Diabetes Res Clin Pract 2010;87:385-393.

-9 Kerr EA, Heisler M, Krein SL, Kabeto M, Langa KM, Weir D, Piette JD: Beyond comorbidity counts: how do comorbidity type and severity influence diabetes patients' treatment priorities and self-management? J Gen Intern Med 2007;22:1635-1640.

10 Miller J, Edwards LD, Agusti A, Bakke P, Calverley PM, Celli B, Coxson HO, Crim C, Lomas DA, Miller BE, et al: Comorbidity, systemic inflammation and outcomes in the ECLIPSE cohort. Respir Med 2013;107:13761384.

-11 Baker EH, Janaway CH, Philips BJ, Brennan AL, Baines DL, Wood DM, Jones PW: Hyperglycaemia is associated with poor outcomes in patients admitted to hospital with acute exacerbations of chronic obstructive pulmonary disease. Thorax 2006;61:284-289.

-12 Parappil A, Depczynski B, Collett P, Marks GB: Effect of comorbid diabetes on length of stay and risk of death in patients admitted with acute exacerbations of COPD. Respirology 2010;15:918-922.

13 Cao C, Wang R, Wang J, Bunjhoo H, Xu Y, Xiong W: Body mass index and mortality in chronic obstructive pulmonary disease: a meta-analysis. PLoS One 2012;7:e43892.

14 Divo M, Cote C, de Torres JP, Casanova C, Marin JM, Pinto-Plata V, Zulueta J, Cabrera C, Zagaceta J, Hunninghake G, et al: Comorbidities and risk of mortality in patients with chronic obstructive pulmonary disease. Am J Respir Crit Care Med 2012;186:155-161.

15 Rana JS, Mittleman MA, Sheikh J, Hu FB, Manson JE, Colditz GA, Speizer FE, Barr RG, Camargo CA Jr: Chronic obstructive pulmonary disease, asthma, and risk of type 2 diabetes in women. Diabetes Care 2004;27:24782484.

16 Lee CT, Mao IC, Lin CH, Lin SH, Hsieh MC: Chronic obstructive pulmonary disease: a risk factor for type 2 diabetes: a nationwide population-based study. Eur J Clin Invest 2013;43: 1113-1119.

-17 Song Y, Klevak A, Manson JE, Buring JE, Liu S: Asthma, chronic obstructive pulmonary disease, and type 2 diabetes in the Women's Health Study. Diabetes Res Clin Pract 2010; 90:365-371.

18 Shah SH, Sonawane P, Nahar P, Vaidya S, Salvi S: Pulmonary function tests in type 2 diabetes mellitus and their association with glycemic control and duration of the disease. Lung India 2013;30:108-112.

19 Litonjua AA, Lazarus R, Sparrow D, Demolles D, Weiss ST: Lung function in type 2 diabetes: the Normative Aging Study. Respir Med 2005; 99:1583-1590. 
20 Aparna: Pulmonary function tests in type 2 diabetics and non-diabetic people - a comparative study. J Clin Diagn Res 2013;7:16061608.

-21 Dennis RJ, Maldonado D, Rojas MX, Aschner $\mathrm{P}$, Rondon M, Charry L, Casas A: Inadequate glucose control in type 2 diabetes is associated with impaired lung function and systemic inflammation: a cross-sectional study. BMC Pulm Med 2010;10:38.

22 Lawlor DA, Ebrahim S, Smith GD: Associations of measures of lung function with insulin resistance and type 2 diabetes: findings from the British Women's Heart and Health Study. Diabetologia 2004;47:195-203.

-23 Lim SY, Rhee EJ, Sung KC: Metabolic syndrome, insulin resistance and systemic inflammation as risk factors for reduced lung function in Korean nonsmoking males. J Korean Med Sci 2010;25:1480-1486.

-24 Davis WA, Knuiman M, Kendall P, Grange V, Davis TM: Glycemic exposure is associated with reduced pulmonary function in type 2 diabetes: the Fremantle Diabetes Study. Diabetes Care 2004;27:752-757.

-25 Kinney GL, Black-Shinn JL, Wan ES, Make B, Regan E, Lutz S, Soler X, Silverman EK, Crapo J, Hokanson JE; COPDGene Investigators: Pulmonary function reduction in diabetes with and without chronic obstructive pulmonary disease. Diabetes Care 2014;37:389-395.

26 Lange P, Parner J, Schnohr P, Jensen G: Copenhagen City Heart Study: longitudinal analysis of ventilatory capacity in diabetic and nondiabetic adults. Eur Respir J 2002;20: 1406-1412.

-27 Forgiarini LA Jr, Kretzmann NA, Porawski M, Dias AS, Marroni NA: Experimental diabetes mellitus: oxidative stress and changes in lung structure. J Bras Pneumol 2009;35:788791.

28 Vracko R, Thorning D, Huang TW: Basal lamina of alveolar epithelium and capillaries: quantitative changes with aging and in diabetes mellitus. Am Rev Respir Dis 1979;120: 973-983.

29 Esposito K, Nappo F, Marfella R, Giugliano G, Giugliano F, Ciotola M, Quagliaro L, Ceriello A, Giugliano D: Inflammatory cytokine concentrations are acutely increased by hyperglycemia in humans: role of oxidative stress. Circulation 2002;106:2067-2072.

- 30 Andreozzi F, Succurro E, Mancuso MR, Perticone M, Sciacqua A, Perticone F, Sesti G: Metabolic and cardiovascular risk factors in subjects with impaired fasting glucose: the 100 versus $110 \mathrm{mg} / \mathrm{dl}$ threshold. Diabetes Metab Res Rev 2007;23:547-550.

- 31 Choi KM, Lee J, Lee KW, Seo JA, Oh JH, Kim SG, Kim NH, Choi DS, Baik SH: Comparison of serum concentrations of C-reactive protein, TNF-alpha, and interleukin 6 between elderly Korean women with normal and impaired glucose tolerance. Diabetes Res Clin Pract 2004;64:99-106.

- 32 Ehrlich SF, Quesenberry CP Jr, Van Den Eeden SK, Shan J, Ferrara A: Patients diag- nosed with diabetes are at increased risk for asthma, chronic obstructive pulmonary disease, pulmonary fibrosis, and pneumonia but not lung cancer. Diabetes Care 2010;33:5560.

-33 Makarevich AE, Valevich VE, Pochtavtsev $\mathrm{AU}$ : Evaluation of pulmonary hypertension in COPD patients with diabetes. Adv Med Sci 2007;52:265-272.

- 34 Burgel PR, Escamilla R, Perez T, et al: Impact of comorbidities on COPD-specific healthrelated quality of life. Respir Med 2013;107: 233-241.

35 Wang Y, Stavem K, Dahl FA, Humerfelt S, Haugen T: Factors associated with a prolonged length of stay after acute exacerbation of chronic obstructive pulmonary disease (AECOPD). Int J Chron Obstruct Pulmon Dis 2014;9:99-105.

-36 Gudmundsson G, Ulrik CS, Gislason T, Lindberg E, Brondum E, Bakke P, Janson C: Longterm survival in patients hospitalized for chronic obstructive pulmonary disease: a prospective observational study in the Nordic countries. Int J Chron Obstruct Pulmon Dis 2012;7:571-576.

37 Gudmundsson G, Gislason T, Lindberg E, Hallin R, Ulrik CS, Brondum E, Nieminen MM, Aine T, Bakke P, Janson C: Mortality in COPD patients discharged from hospital: the role of treatment and co-morbidity. Respir Res 2006;7:109.

-38 Koskela HO, Salonen PH, Niskanen L: Hyperglycaemia during exacerbations of asthma and chronic obstructive pulmonary disease. Clin Respir J 2013;7:382-389.

39 Habib G, Dar-Esaif Y, Bishara H, Artul S, Badarny S, Chernin M, Jabbour A: The impact of corticosteroid treatment on hemoglobin A1C levels among patients with type-2 diabetes with chronic obstructive pulmonary disease exacerbation. Respir Med 2014;108: 1641-1646.

40 Burt MG, Roberts GW, Aguilar-Loza NR, Quinn SJ, Frith PA, Stranks SN: Relationship between glycaemia and length of hospital stay during an acute exacerbation of chronic obstructive pulmonary disease. Intern Med J 2013;43:721-724.

-41 Capes SE, Hunt D, Malmberg K, Gerstein HC: Stress hyperglycaemia and increased risk of death after myocardial infarction in patients with and without diabetes: a systematic overview. Lancet 2000;355:773-778.

42 Capes SE, Hunt D, Malmberg K, Pathak P, Gerstein HC: Stress hyperglycemia and prognosis of stroke in nondiabetic and diabetic patients: a systematic overview. Stroke 2001;32: 2426-2432.

43 Kasirye Y, Simpson M, Mamillapalli CK, Epperla $\mathrm{N}$, Liang $\mathrm{H}$, Yale $\mathrm{SH}$ : Association between blood glucose level and outcomes in patients hospitalized for acute exacerbation of chronic obstructive pulmonary disease. WMJ 2013;112:244-249; quiz 250.

44 Moretti M, Cilione C, Tampieri A, Fracchia C, Marchioni A, Nava S: Incidence and causes of non-invasive mechanical ventilation failure after initial success. Thorax 2000;55:819-825.

45 Chakrabarti B, Angus RM, Agarwal S, Lane S Calverley PM: Hyperglycaemia as a predictor of outcome during non-invasive ventilation in decompensated COPD. Thorax 2009;64: 857-862.

46 Singanayagam A, Schembri S, Chalmers JD: Predictors of mortality in hospitalized adults with acute exacerbation of chronic obstructive pulmonary disease. Ann Am Thorac Soc 2013;10:81-89.

47 McGhan R, Radcliff T, Fish R, Sutherland ER, Welsh C, Make B: Predictors of rehospitalization and death after a severe exacerbation of COPD. Chest 2007;132:1748-1755.

48 Loukides S, Polyzogopoulos D: The effect of diabetes mellitus on the outcome of patients with chronic obstructive pulmonary disease exacerbated due to respiratory infections. Respiration 1996;63:170-173.

49 Brennan AL, Gyi KM, Wood DM, Johnson J, Holliman R, Baines DL, Philips BJ, Geddes DM, Hodson ME, Baker EH: Airway glucose concentrations and effect on growth of respiratory pathogens in cystic fibrosis. J Cyst Fibros 2007;6:101-109.

50 Marhoffer W, Stein M, Maeser E, Federlin K: Impairment of polymorphonuclear leukocyte function and metabolic control of diabetes. Diabetes Care 1992;15:256-260.

51 Hunt WR, Zughaier SM, Guentert DE, Shenep MA, Koval M, McCarty NA, Hansen JM: Hyperglycemia impedes lung bacterial clearance in a murine model of cystic fibrosis-related diabetes. Am J Physiol Lung Cell Mol Physiol 2014;306:L43-L49.

52 Jones PW, Nadeau G, Small M, Adamek L: Characteristics of a COPD population categorised using the GOLD framework by health status and exacerbations. Respir Med 2014; 108:129-135.

53 Sode BF, Dahl M, Nordestgaard BG: Myocardial infarction and other co-morbidities in patients with chronic obstructive pulmonary disease: a Danish nationwide study of 7.4 million individuals. Eur Heart J 2011;32:2365-2375.

54 Feary JR, Rodrigues LC, Smith CJ, Hubbard RB, Gibson JE: Prevalence of major comorbidities in subjects with COPD and incidence of myocardial infarction and stroke: a comprehensive analysis using data from primary care. Thorax 2010;65:956-962.

- 55 Cazzola M, Bettoncelli G, Sessa E, Cricelli C, Biscione G: Prevalence of comorbidities in patients with chronic obstructive pulmonary disease. Respiration 2010;80:112-119.

56 Lazarus R, Sparrow D, Weiss ST: Baseline ventilatory function predicts the development of higher levels of fasting insulin and fasting insulin resistance index: the Normative Aging Study. Eur Respir J 1998;12:641-645.

57 Engstrom G, Hedblad B, Nilsson P, Wollmer P, Berglund G, Janzon L: Lung function, insulin resistance and incidence of cardiovascular disease: a longitudinal cohort study. J Intern Med 2003;253:574-581. 
58 Engstrom G, Janzon L: Risk of developing diabetes is inversely related to lung function: a population-based cohort study. Diabet Med 2002;19:167-170.

59 Eriksson KF, Lindgarde F: Poor physical fitness, and impaired early insulin response but late hyperinsulinaemia, as predictors of NIDDM in middle-aged Swedish men. Diabetologia 1996;39:573-579.

60 Yeh HC, Punjabi NM, Wang NY, Pankow JS, Duncan BB, Brancati FL: Vital capacity as a predictor of incident type 2 diabetes: the Atherosclerosis Risk in Communities Study. Diabetes Care 2005;28:1472-1479.

61 Kwon CH, Rhee EJ, Song JU, Kim JT, Kwag $\mathrm{HJ}$, Sung KC: Reduced lung function is independently associated with increased risk of type 2 diabetes in Korean men. Cardiovasc Diabetol 2012;11:38.

62 Heianza Y, Arase Y, Tsuji H, Saito K, Amakawa K, Hsieh SD, Kodama S, Shimano H, Yamada N, Hara S, Sone H: Low lung function and risk of type 2 diabetes in Japanese men: the Toranomon Hospital Health Management Center Study 9 (TOPICS 9). Mayo Clin Proc 2012;87:853-861.

-63 Ford ES, Mannino DM, National H: Prospective association between lung function and the incidence of diabetes: findings from the National Health and Nutrition Examination Survey Epidemiologic Follow-Up Study. Diabetes Care 2004;27:2966-2970.

-64 Wannamethee SG, Shaper AG, Rumley A, Sattar N, Whincup PH, Thomas MC, Lowe GD: Lung function and risk of type 2 diabetes and fatal and nonfatal major coronary heart disease events: possible associations with inflammation. Diabetes Care 2010;33:19901996.

-65 Joo H, Park J, Lee SD, Oh YM: Comorbidities of chronic obstructive pulmonary disease in Koreans: a population-based study. J Korean Med Sci 2012;27:901-906.

66 Park SK, Larson JL: The relationship between physical activity and metabolic syndrome in people with chronic obstructive pulmonary disease. J Cardiovasc Nurs 2014; 29:499-507.

67 Shah S: Frequency of Metabolic syndrome and its relationship with systemic inflammation in patients of chronic obstructive pulmonary disease (COPD) in ethnic Kashmiri population of India. Chest 2014;145:400A

-68 Akpinar EE, Akpinar S, Ertek S, Sayin E, Gulhan M: Systemic inflammation and metabolic syndrome in stable COPD patients. Tuberk Toraks 2012;60:230-237.

69 Schmidt MI, Duncan BB, Sharrett AR, Lindberg G, Savage PJ, Offenbacher S, Azambuja MI, Tracy RP, Heiss G: Markers of inflammation and prediction of diabetes mellitus in adults (Atherosclerosis Risk in Communities Study): a cohort study. Lancet 1999;353: 1649-1652.

70 Barzilay JI, Abraham L, Heckbert SR, Cushman M, Kuller LH, Resnick HE, Tracy RP: The relation of markers of inflammation to the development of glucose disorders in the elderly: the Cardiovascular Health Study. Diabetes 2001;50:2384-2389.

-71 Bolton CE, Evans M, Ionescu AA, Edwards SM, Morris RH, Dunseath G, Luzio SD, Owens DR, Shale DJ: Insulin resistance and inflammation - a further systemic complication of COPD. COPD 2007;4:121-126.

72 Duncan BB, Schmidt MI, Pankow JS, Ballantyne CM, Couper D, Vigo A, Hoogeveen R, Folsom AR, Heiss G: Low-grade systemic inflammation and the development of type 2 diabetes: the Atherosclerosis Risk in Communities Study. Diabetes 2003;52:17991805.

73 Pradhan AD, Manson JE, Rifai N, Buring JE, Ridker PM: C-reactive protein, interleukin 6, and risk of developing type 2 diabetes mellitus. JAMA 2001;286:327-334.

74 Takenaka S, Kawayama T, Imaoka H, Sakazaki Y, Oda H, Kaku Y, Matsuoka M, Okamoto M, Kato S, Yamada K, Hoshino T: The progression of comorbidity in IL-18 transgenic chronic obstructive pulmonary disease mice model. Biochem Biophys Res Commun 2014;445:597-601.

75 Bayliss EA, Blatchford PJ, Newcomer SR, Steiner JF, Fairclough DL: The effect of incident cancer, depression and pulmonary disease exacerbations on type 2 diabetes control. J Gen Intern Med 2011;26:575-581.

76 Groenewegen KH, Schols AM, Wouters EF: Mortality and mortality-related factors after hospitalization for acute exacerbation of COPD. Chest 2003;124:459-467.

-77 Caughey GE, Preiss AK, Vitry AI, Gilbert AL, Roughead EE: Comorbid diabetes and COPD: impact of corticosteroid use on diabetes complications. Diabetes Care 2013;36: 3009-3014.

78 Slatore CG, Bryson CL, Au DH: The association of inhaled corticosteroid use with serum glucose concentration in a large cohort. Am J Med 2009;122:472-478.

79 Suissa S, Kezouh A, Ernst P: Inhaled corticosteroids and the risks of diabetes onset and progression. Am J Med 2010;123:1001-1006.

-80 Niewoehner DE, Erbland ML, Deupree RH, Collins D, Gross NJ, Light RW, Anderson P, Morgan NA: Effect of systemic glucocorticoids on exacerbations of chronic obstructive pulmonary disease. Department of Veterans Affairs Cooperative Study Group. N Engl J Med 1999;340:1941-1947.

-81 Burt MG, Roberts GW, Aguilar-Loza NR, Frith P, Stranks SN: Continuous monitoring of circadian glycemic patterns in patients receiving prednisolone for COPD. J Clin Endocrinol Metab 2011;96:1789-1796.

82 Blackburn D, Hux J, Mamdani M: Quantification of the risk of corticosteroid-induced diabetes mellitus among the elderly. J Gen Intern Med 2002;17:717-720.

83 Dendukuri N, Blais L, LeLorier J: Inhaled corticosteroids and the risk of diabetes among the elderly. Br J Clin Pharmacol 2002;54:5964.
84 O’Byrne PM, Rennard S, Gerstein H, Radner F, Peterson S, Lindberg B, Carlsson LG, Sin DD: Risk of new onset diabetes mellitus in patients with asthma or COPD taking inhaled corticosteroids. Respir Med 2012;106:14871493.

85 Walters JA, Gibson PG, Wood-Baker R, Hannay M, Walters EH: Systemic corticosteroids for acute exacerbations of chronic obstructive pulmonary disease. Cochrane Database Syst Rev 2009;CD001288.

-86 Leuppi JD, Schuetz P, Bingisser R, Bodmer M, Briel M, Drescher T, Duerring U, Henzen C, Leibbrandt Y, Maier S, et al: Short-term vs. conventional glucocorticoid therapy in acute exacerbations of chronic obstructive pulmonary disease: the REDUCE randomized clinical trial. JAMA 2013;309:2223-2231.

87 Ceviker Y, Sayiner A: Comparison of two systemic steroid regimens for the treatment of COPD exacerbations. Pulm Pharmacol Ther 2014;27:179-183.

88 Cheng T, Gong Y, Guo Y, Cheng Q, Zhou M, Shi G, Wan H: Systemic corticosteroid for COPD exacerbations, whether the higher dose is better? A meta-analysis of randomized controlled trials. Clin Respir J 2013;7:305-318.

89 Anton E: How and when to use inhaled corticosteroids in chronic obstructive pulmonary disease? Expert Rev Respir Med 2013;7:2532.

90 Piatti P, Setola E, Galluccio E, Costa S, Fontana B, Stuccillo M, Crippa V, Cappelletti A, Margonato A, Bosi E, Monti LD: Smoking is associated with impaired glucose regulation and a decrease in insulin sensitivity and the disposition index in first-degree relatives of type 2 diabetes subjects independently of the presence of metabolic syndrome. Acta Diabetol 2014;51:793-799.

91 Drozdovszky O, Barta I, Antus B: Sputum eicosanoid profiling in exacerbations of chronic obstructive pulmonary disease. Respiration 2014;87:408-415.

92 Grubek-Jaworska H, Paplinska M, Hermanowicz-Salamon J, Bialek-Gosk K, Dabrowska M, Grabczak E, Domagala-Kulawik J, Stepien J, Chazan R: IL-6 and IL-13 in induced sputum of COPD and asthma patients: correlation with respiratory tests. Respiration 2012; 84:101-107.

-93 Criner GJ, Connett JE, Aaron SD, Albert RK Bailey WC, Casaburi R, Cooper JA Jr, Curtis JL, Dransfield MT, Han MK, et al: Simvastatin for the prevention of exacerbations in moderate-to-severe COPD. N Engl J Med 2014;370: 2201-2210.

94 Archer JR, Misra S, Simmgen M, Jones PW, Baker EH: Phase II study of tight glycaemic control in COPD patients with exacerbations admitted to the acute medical unit. BMJ Open 2011;1:e00210.

95 Morrish NJ, Wang SL, Stevens LK, Fuller JH, Keen H: Mortality and causes of death in the WHO Multinational Study of Vascular Disease in Diabetes. Diabetologia 2001;44(suppl 2): S14-S21. 